\title{
A relação escritor-leitor nas obras do OuLiPo
}

\author{
Natália Ubirajara Silva ${ }^{\mathrm{i}}$ \\ Virgínia Crivellaro Sanchotene ${ }^{\mathrm{ii}}$
}

\section{RESUMO}

O presente artigo tem como objetivo estudar a relação entre escritor e leitor nas obras do grupo francês OuLiPo. Formada por escritores e matemáticos, essa Oficina de Literatura Potencial propõe uma literatura com bases matemáticas através do inventário e da invenção de contraintes - regras ou restrições autoimpostas. A partir da discussão dos conceitos de jogo, arquitetura labiríntica, imanência, coleção e dialogismo, bem como da análise de algumas obras de autores do grupo, questionamos o papel do leitor nesse jogo.

Palavras-chave: OuLiPo; Literatura potencial; Contrainte; Combinatória; Diálogo escritor-leitor.

\begin{abstract}
This article aims to study the relationship between writer and reader in the works of the French group OuLiPo. Formed by writers and mathematicians, this Potential Literature Workshop proposes a literature of mathematical foundations through the inventory and invention of contraintes - self-imposed rules or restrictions. Departing from a discussion of the concepts of game, labyrinthic architecture, immanence, collection and dialogism, as well as from an analysis of some works by authors from the group, we are going to question the role of the reader in this game.
\end{abstract}

Keywords: OuLiPo; Potential literature; Contrainte; Combinatorics; Writer-reader dialogue.

\footnotetext{
${ }^{i}$ Doutora em Literaturas Portuguesa e Luso-africana (UFRGS, 2016), mestre em Literatura Brasileira e Portuguesa (UFRGS, 2009), licenciada em Português e Literaturas de Língua Portuguesa (UFRGS, 2005). Professora na rede de educação municipal de Porto Alegre desde 2012. | https://orcid.org/0000-0002$\underline{6575-1249}$ | natisil1@gmail.com

ii Doutoranda em Educação (UFRGS). Mestre em Educação (UFRGS, 2013). Licenciada em Matemática (UFRGS, 2009). Professora de Matemática da rede municipal de ensino de Porto Alegre. I prof.virginia.mat@gmail.com
} 


\section{INTRODUÇÃO}

O presente trabalho tem como objetivo estudar a relação entre escritor e leitor nas produções do grupo francês OuLiPo (Ouvroir de Littérature Potentielle - Oficina ou Laboratório de Literatura Potencial). Formado em 1960 por escritores e matemáticos, o grupo é reconhecido até hoje pela proposta de "novas 'estruturas' de natureza matemática ou novos procedimentos que contribuíssem com a atividade literária" (PINO, 2004, p. 50), em contraponto à inspiração e ao automatismo. A fortuna crítica geralmente aborda a estrutura dos trabalhos oulipianos (os procedimentos neles resgatados ou instaurados); interessa-nos, no presente artigo, compreender de que forma essa estrutura possibilita o diálogo com o leitor.

\section{O JOGO OULIPIANO: INVENTÁRIO E CRIAÇÃO}

Os escritores oulipianos operam na transposição da axiomática e suas determinações para o campo da Literatura, instaurando um "espaço de experimentação poético-matemática" (PEREIRA, 2012, p. 121). As experimentações do OuLiPo se dão por meio de contraintes, métodos restritivos que possibilitam a incorporação de estruturas matemáticas em trabalhos literários (FUX, 2016, p. 29-30); trata-se de travas ou regras autoimpostas que servem como disparo para as obras.

Ao propor uma escrita regrada, liberta da inspiração, o OuLiPo opõe-se às vanguardas literárias do início do século $\mathrm{XX}$ - principalmente ao movimento surrealista, que preconizava a escrita inconsciente e automática (PEREIRA, 2012, p. 120). No Surrealismo, "o homem se instalou no centro da criação e reclama sua liberdade absoluta" (MOLINA, 1999, p. 23); André Breton, líder do movimento, propunha que se escrevesse um "ditado do pensamento, na ausência de todo controle exercido pela razão" (BRETON, s.d.). É em contraposição à liberdade absoluta, ao automatismo e ao acaso (enquanto aleatoriedade) que o OuLiPo propõe o uso de contraintes. Como aponta Carneiro (2012, p. 103), a produção literária do OuLiPo não resulta de experimentação livre, mas daquilo que o matemático oulipiano Claude Berge (apud JAMES, 2009, p. 110) chama de anti-hasard (antiacaso) ou défi au hasard (desafio ao acaso) - mas esse antiacaso não nega o jogo das circunstâncias. James 
(2009, p. 126) sublinha que, segundo a análise genettiana, as experimentações oulipianas trabalham com um tipo particular de acaso, oriundo de uma intenção; isso porque os textos produzidos pelo OuLiPo nascem a partir de uma experimentação regrada, calcada na repetição e criação de restrições algébricas.

Em Matemática, a potenciação é a recorrência da multiplicação. Assim, a escrita oulipiana pode ser considerada potente por proliferar sentidos combinatórios, arranjamentos que se dão por um processo multiplicativo. Seu caráter potencial, portanto, permite que "com uma pequena quantidade de matéria e mecanismos, [...] [se possa fornecer] uma enorme vastidão de novas obras" (CARNEIRO, 2012, p. 103). Quanto a isso, não se pode negar a fecundidade dos métodos oulipianos, visto que até mesmo existiram extensões de seu trabalho a outros campos da linguagem literária, como o OuBaPo, uma Oficina de História em Quadrinhos Potencial (CARNEIRO, 2012). Segundo Carneiro (2012, p. 102), o OuLiPo, "desfazendo a ideia de que a literatura é a arte do único e do inimitável, explora o potencial teórico, ao mesmo tempo em que obviamente poético ou criativo, de uma lógica da repetição e da imitação". Defende-se, pois, que a repetição pode ser criativa.

Carneiro resume a proposta oulipiana:

\footnotetext{
Revigorando técnicas da antiga retórica, capazes de romper com a crença na inspiração, no gênio ou no subconsciente, como motores da criação, [os oulipianos] queriam, principalmente, encontrar estruturas inéditas e promover pesquisas sobre as potencialidades da linguagem, estabelecendo relações entre matemática e literatura. (2012, p. 103)
}

Desse modo, vemos que o trabalho oulipiano se baseia em duas vertentes complementares: a pesquisa analítica e a sintética (PINO, 2004, p. 50). No ramo analítico, busca-se inventariar procedimentos e regras, ao passo que a pesquisa sintética visa à criação de novas regras.

A partir do estudo dos textos de autores oulipianos e seus comentadores, é recorrente a relação entre escrita e jogo. Mas em que consiste tomar o texto literário como jogo? Quais os sentidos para a palavra jogo aqui? Jogo (do latim jocu) significa divertimento, brincadeira, atividade lúdica realizada por prazer ou competição e que pressupõe regras, lances e técnica. O vocábulo jogo, portanto, faz referência a uma atividade estruturada composta obrigatoriamente por regras, acontecendo dentro de limiares de tempo, espaço e recursos determinados. A função do jogador, do escritor- 
jogador nesse caso, ao aceitar as regras, passa por analisar as possibilidades, arriscar-se nos lances, tomar decisões, criar estratégias ou artifícios considerando os recursos que lhe cabem, impostos pela linguagem e pelas regras consentidas. O espaço, o tempo e a linguagem são inescapáveis.

Assumindo sua escrita como jogo, partindo de uma estruturação fundada em contraintes ou regras e inscrevendo sua literatura em bases matemáticas, os oulipianos de vertente analítica ou sintética produzem quatro tipos de texto (CARNEIRO, 2012, p. 102-103): textos baseados em estruturas preexistentes (rondós, sonetos, haicais); textos escritos a partir de contraintes criadas pelos oulipianos; exercícios de estilo, pastiches e paródias; e textos de literatura combinatória. Essa tipologia não é estanque: ao ler as produções do grupo, percebe-se que um tipo de texto está imbricado no outro.

Nem toda restrição que o OuLiPo propõe é original. Em sua pesquisa analítica, os oulipianos inventariam procedimentos e regras empregados antes da fundação do grupo, e essa investigação revela que, de certa forma, a escrita sob contraintes já existia na Literatura. A métrica e os poemas de forma fixa (baladas, quadras, vilancetes, rondós, haicais e sonetos) são estruturas tradicionais precursoras das restrições algébricas oulipianas - e os membros do OuLiPo, jocosamente, referem-se a seus predecessores no uso de contraintes como "plagiadores por antecipação". Por meio dos padrões fixos tradicionais, podem-se criar textos ilimitados; o caráter potencial e regrado destacado pelo OuLiPo, portanto, pertence à própria Literatura. Os membros do laboratório de literatura potencial exploram as possibilidades oferecidas pelas formas fixas preexistentes, levando-as ao limite: é o que fazem Raymond Queneau (em Cent mille milliards de poèmes, 1961) e Georges Perec (em Palindrome, 2019, palíndromo composto por mais de cinco mil palavras), por exemplo.

A diferença entre as regras tradicionais e as criadas pelo grupo francês reside no papel que as restrições autoimpostas pelo escritor assumem nas oficinas oulipianas. Enquanto, na tradição literária, as formas fixas são apenas suporte para o conteúdo, nas produções do OuLiPo as contraintes são "a matriz geradora do fenômeno textual" (PEREIRA, 2012, p. 122). Nos textos escritos a partir de contraintes, os oulipianos valorizam "o caráter material da literatura e a imanência do texto como brincadeira de significantes, análoga à manipulação de variáveis em uma equação” (PEREIRA, 2012, p. 122). A área da Matemática que trata da resolução de equações pela manipulação de 
seus termos é chamada de Álgebra; responsável pela generalização da Aritmética, a Álgebra estuda propriedades das estruturas matemáticas.

O termo álgebra deriva do título do livro Hisob al-jabr wa'l muqabalha (c. 830 d.C.), de Al-Khwarizmi, obra responsável por difundir pela Europa o campo da Matemática que recebe esse nome. De acordo com Boyer,

\footnotetext{
A palavra al-jabr presumivelmente significa algo como 'restauração' ou 'completação' [sic] e parece referir-se à transposição de termos subtraídos para o outro lado da equação [...]. A influência árabe na Espanha, muito depois do tempo de Al-Khwarizmi, pode ser vista em Dom Quixote, em que a palavra algebrista é usada para indicar um 'restaurador' de ossos. (2012, p. 166)
}

Tomar a escrita à luz da Álgebra pode ser considerado como assumir suas restrições estruturais e manipular seus termos - constantes, incógnitas ou variáveis através de regras determinadas. Equacionar é o ato de transformar um problema em uma expressão matemática solucionável por procedimentos definidos e compartilháveis, produzindo sempre associações. É por associação, pela reunião de elementos diversos, por conexão - e aqui se destaca o trabalho do restaurador - que se soluciona uma equação.

Desse modo, escrever ao modo de um algebrista é encarar as incógnitas do problema (nesse caso, impostas pela contrainte), dispô-las sobre o papel e manipulá-las formalmente, segundo as regras acordadas, a fim de obter um resultado - para os oulipianos, o texto. Ao produzir um lipograma, podemos pensar na fórmula $\mathrm{n}$ - 1 , em que existem 26 opções para n (a saber, as letras do alfabeto). A contrainte $\mathrm{S}+7$, de Jean Lescure, já assume a algebrização no nome. Para os autores-algebristas, o objetivo de criar contraintes e escrever seguindo essas regras é, paradoxalmente, "libertar a escrita" (PEREIRA, 2012, p. 121).

O terceiro tipo de texto produzido pelo OuLiPo são os exercícios de estilo ou pastiches. O pastiche é um gênero hipertextual - na acepção genettiana - baseado na imitação do estilo de um texto anterior (hipotexto). Diferencia-se da paródia, que é um hipertexto fundado na transformação do hipotexto (GENETTE, 2006, p. 20). Ambos os gêneros têm caráter lúdico, oscilando entre a ironia e o humor (GENETTE, 2006, p. 2526), e pertencem ao âmbito da bricolagem, fazendo "o velho com o novo" (GENETTE, 2006, p. 45). Uma das maiores referências ao se estudar pastiche e paródia oulipianos é 
o livro Exercícios de estilo (1995) - o que não deixa de ser curioso, uma vez que essa obra foi publicada em 1947, treze anos antes da fundação do OuLiPo. O livro é um hipertexto híbrido, no qual Raymond Queneau pasticha e parodia 99 modos diferentes de se contar a mesma história. Por sua vez, Jacques Roubaud parodia a narrativa policial detetivesca (A bela Hortense, 1993), a novela de cavalaria (Graal fiction, 1978) e o bestiário (Os animais de todo mundo, 2006).

Dentre as produções oulipianas, há ainda os textos de literatura combinatória. A Análise Combinatória é a parte da Matemática que estuda o número de possibilidades que podem acontecer numa experimentação. Trata-se de um ramo que faz a análise das possibilidades e das combinações possíveis entre um conjunto de elementos, em que é possível arranjar (quando a ordem dos elementos importa), combinar (quando a ordem dos elementos não importa) ou permutar, dependendo do problema enunciado - ou, no caso do texto, da regra acordada.

Nos textos de literatura combinatória, parte-se do princípio de que a língua se estabelece a partir de regras de combinatória, como as associações substantivo-adjetivo, verbo-advérbio, etc. As palavras são, já, expansões combinatórias de 26 elementos iniciais - as letras. Sem considerarmos regras específicas da Língua Portuguesa, temos 650 possibilidades de combinar duas letras distintas, 15.600 possibilidades de combinar três letras distintas, 358.800 possibilidades de combinar quatro letras distintas e quase oito milhões de possibilidades de combinar cinco letras distintas - isso, desconsiderando palavras com letras que se repetem. Ao permitirmos apenas uma repetição, esse número aumenta para mais de nove milhões. Pensar nas expansões de possibilidades de grafar uma palavra nos mostra a potencialidade do uso da combinatória. A arbitrariedade dos significantes assumidos por nossa língua forma um subconjunto restringido por espécies de contraintes, de regras combinatórias. A combinatória não se restringe aos modos de escrever uma palavra. Para os autores oulipianos, ela se expande para as relações possíveis palavra-palavra - sob regras não somente semânticas ou fonéticas, mas também morfológicas e sintáticas. As classes gramaticais, por exemplo, são elementos restritivos, bem como a estrutura frasal da oração.

O maior exemplo de literatura potencial oulipiana é Cent mille milliards de poèmes, hiper-soneto (TAVARES, 2004) publicado por Raymond Queneau em 1961. O 
livro, impresso em tiras, apresenta dez sonetos com esquema ABAB-ABAB-CCD-EED; cada primeiro verso pode se encadear com todos os segundos versos e assim sucessivamente. Este é um exemplo de escrita combinatória que se utiliza do Princípio Fundamental da Contagem, ou Princípio Multiplicativo: um soneto tem 14 versos; então, nosso evento é composto por $n=14$ etapas sucessivas e independentes, com $x=10$ possibilidades cada. Dadas as condições fixadas de que as etapas são sucessivas e independentes, não utilizamos nem combinação, nem arranjo, nem permutação, mas o Princípio acima referido. Ou seja, por um processo de recorrência multiplicativa, alcançamos a potenciação - o leitor tem diante de si não dez, mas $10^{14}$ sonetos. É importante assinalar que Cent mille milliards de poèmes, bem como diversas outras obras oulipianas, acumula mais de uma tipologia. Trata-se de um soneto - portanto, baseia-se em uma estrutura preexistente -, mas também se abre a uma leitura combinatória.

\section{ARQUITETURA DE UM LABIRINTO}

A aproximação entre literatura e jogo estratégico "faz com que, consequentemente, tomemos a obra literária como fruto de construção, burilamento, trabalho" (SILVA, 2009, p. 65). Consideramos a escrita oulipiana uma arquitetura: os autores engendram suas obras assumindo o projeto estrutural que advém da Matemática, resultando em uma construção que extrapola esses limiares, tornando-se Literatura. Essa arquitetura é labiríntica:

E um AUTOR oulipiano, o que é ele? É 'um rato que constrói para si mesmo o labirinto do qual se propõe a sair'. Um labirinto de quê? De palavras, de sons, de frases, de parágrafos, de capítulos, de livros, de bibliotecas, de prosa, de poesia, e tudo isso... (BÉNABOU; ROUBAUD, s.d.). ${ }^{1}$

O labirinto tem por função entrelaçar: ele disponibiliza referências diversas e obriga o escritor, como algebrista, a subtrair elementos dessa disposição. E subtrair, aqui, não diminui, mas ao contrário, evidencia. É pela escolha do percurso a seguir que o autor se vale do caminho múltiplo e multiplicativo do labirinto, num jogo alusivo entre predecessores, obras, regras, combinações. O trajeto se faz por combinações; mais especificamente, faz-se por arranjos, em meio "à sua natureza gráfica de traçado 
aporético e de caminho mais longo encerrado no espaço mais curto" (DETIENNE, 1991, p. 13). Se o arquiteto oulipiano constrói seu próprio labirinto, é por sua capacidade de arranjar, de inscrever seu texto no terreno da combinatória, em contrapartida à linearidade de um percurso de uma escrita automática ou inspirada.

Nessa lógica, as restrições iniciais assumidas pelos escritores servem de estruturação para a escrita, mas não determinam o percurso. É pelas relações que estabelece, pelo uso de suas referências, que o oulipiano faz escolhas. Essas alternativas encontradas ou construídas pelo autor dependem diretamente da experimentação. De acordo com Machado (2008, p. 255), “O labirinto originalmente, na Grécia, era um ambiente de experimentação, não uma prisão, onde seu percurso era mais importante que a saída". Nesse conjunto de percursos possíveis, a experimentação entra em jogo, a experimentação se faz jogo; é "a produção, antes do produto, que conta aqui" (PEREIRA, 2012, p. 125). O labirinto é um convite "à exegese, e o entrelaçamento de encruzilhadas e de corredores ramificados atrai irresistivelmente o intérprete a mil e um percursos" (DETIENNE, 1991, p. 13). Para o OuLiPo, o percurso é mais importante que encontrar a saída, o que nos conduz à imanência de sua criação.

\section{A IMANÊNCIA EM JOGO}

Pereira (2012, p. 120) nos apresenta que "o OuLiPo promove uma literatura da imanência”. O que seria uma literatura da imanência? Schöpke (2010) define o sentido de imanência mais empregado nas filosofias contemporâneas:

O termo [imanente] aparece, entre os escolásticos, com o sentido de uma ação que se dá no interior do próprio agente, ao contrário daquela que é exterior e se dá no outro. [...] Imanência, no sentido mais rigoroso do termo, quer dizer, portanto, aquilo que é ontologicamente inerente a alguma coisa. (SCHÖPKE, 2010, p. 134)

Segundo Zourabichvili, em seu $O$ vocabulário de Gilles Deleuze (2004, p. 87), imanente opõe-se a transcendente "porque o plano não precede o que vem povoá-lo ou preenchê-lo, mas é construído e remanejado na experiência". Esse plano de imanência toma o lugar do plano transcendental porque se refere a ele mesmo, em si, e não a algo que existiria além dele. A escrita imanente é aquela que cria para si seu próprio terreno, 
para então habitá-lo, na contramão de um além do texto. Desse modo, uma literatura da imanência se compromete consigo mesma e insere-se como regra do jogo.

A imanência é o solo sobre o qual o labirinto se arquiteta. O plano de imanência, sendo sempre único (enquanto terreno de inscrição), não é nunca totalizante, havendo variados planos de imanência "que se sucedem ou rivalizam" (DELEUZE; GUATTARI, 2010, p. 49). O plano de imanência é "como um corte do caos e age como um crivo" (DELEUZE; GUATTARI, 2010, p. 53). Para o OuLiPo, a contrainte é a regra de construção desses caminhos diversos em solo imanente.

Nessa perspectiva, surge o questionamento: a imanência oulipiana é aquela em que um texto se fecha em si mesmo ou aquela em que o texto, por sua lógica de construção - como um jogo - tem valor por si próprio? A escrita do OuLiPo encerra-se em sua criação ou abre-se à interpretação-participação do leitor - num sentido de interpretação-participação não-transcendente, não dado a priori? Em outras palavras, questionamos se a participação do leitor em obras oulipianas é dispensável ou se ela, apesar de não possuir caráter fundante, dado que a obra é escrita e validada em si mesma, faz-se necessária e, até mesmo, desejável.

\section{A RELAÇÃO ESCRITOR-LEITOR NO JOGO OULIPIANO}

A relação escritor-leitor ou, dito de outra forma, o convite ao leitor para assumir um lugar de jogador na escrita-leitura da obra é o cerne deste artigo. Quantos jogam esse jogo? Tratar-se-ia de um jogo individual?

De acordo com Pereira (2013, p. 190), o exercício oulipiano é um “jogo individual, como o da escrita, o da leitura, ou da paciência". Alguns textos oulipianos se reduzem a rascunhos ou a práticas de desenvolvimento da criatividade - gatilhos criativos - e, desse modo, podem ser entendidos como jogos individuais; outros, contudo, vão além, convidando o leitor ao jogo literário como parceiro ou, até mesmo, adversário. Nesse caso, como frisa James (2009, p. 126), “Os textos oulipianos nos convidam a descobrir sentidos ocultos e, assim, a adotar táticas de leitura que podem ou não espelhar a estratégia do autor". iii Percebemos, portanto, perspectivas diversas

\footnotetext{
iii No original: "Oulipian texts invite us to uncover hidden meanings and thus to engage in reading tactics that may or may not mirror the author's strategy".
} 
quanto à relação com o leitor. Existem os jogos individuais, focados na liberação da escrita; há também os jogos coletivos, que convidam à participação de quem lê.

De que maneira somos convidados a participar, como leitores, dos textos oulipianos? De que forma somos interpelados pelos textos oulipianos? Estabelecendo a distinção entre esses dois modos de compor o texto - o individual e o convidativo -, tentaremos verificar de que forma os textos oulipianos se abrem ao outro.

Quanto ao fazer literário, o OuLiPo apresenta-se como um grupo despretensioso, estabelecendo regras formais que podem "ser propostas a amadores desejosos de produzir textos" (CARNEIRO, 2012, p. 103). Por meio das contraintes criadas, a escrita está ao alcance de todos, ainda que haja diferenças no resultado: Georges Perec ou Italo Calvino, com seu conhecimento dos códigos literários, exploram de forma mais competente as potencialidades que as contraintes oferecem.

Dentro do OuLiPo parece haver diversos papéis:

Que fazem os OULIPIANOS, os membros do OULIPO (Calvino, Perec, Marcel Duchamp, e outros, matemáticos e escritores, escritores-matemáticos, e matemáticos-escritores)? Eles trabalham. (BÉNABOU; ROUBAUD, s.d.; grifo do autor). ${ }^{2}$

Assim, os oulipianos apresentam vários subconjuntos de autoria: matemáticos, literatos, literatos-matemáticos e matemáticos-literatos; os critérios para a determinação das categorias podem estar ligados aos "resultados" das suas obras resultados estes que estão intimamente ligados às regras autoimpostas desde o início da criação. Essa relação causa-efeito, ou contrainte-resultado, aqui, é imanente; portanto, indissociável.

Talvez os matemáticos-literatos sejam bem-sucedidos na criação de contraintes e os literatos-matemáticos sejam os que apresentam textos de maior permanência ou de cunho propriamente literário, como Georges Perec e Italo Calvino - e pode se dever a isso o destaque reiterado, por parte do OuLiPo e de pesquisadores, dos nomes de Perec, Queneau, Calvino e Roubaud como mais relevantes do grupo, exemplos mais acabados do potencial que a literatura sob contraintes pode alcançar.

Segundo Perrone-Moisés (2016, p. 35), seriam literárias as obras que exercitam conscientemente a linguagem, que criam um mundo paralelo, que expressam pensamentos e sentimentos que não são apenas individuais e que formulam perguntas 
relevantes sem a pretensão de respondê-las. Nesse horizonte, analisando os diferentes resultados obtidos com o uso das contraintes, são principalmente os textos de Perec, Queneau, Calvino e Roubaud que se revestem de cariz literário.

Os membros do OuLiPo talvez respondessem que essa discussão é irrelevante pois, como assinala Pereira (2012, p. 121), “o cerne de suas discussões não seria a produção de 'Grande Literatura' - os chefs d'oeuvres, em oposição aos pieds d'oeuvres [...]. Em vez disso, a ideia oulipiana era a de uma escrita lúdica”, cujos textos escapam à “teleologia da escrita" (PEREIRA, 2012, p. 134), ou seja, não têm uma finalidade extratextual:

\footnotetext{
Vagar pelo imbricado percurso determinado pela contrainte, urdindo um fio textual que não se confunde com o de Ariadne é, para o autor oulipiano, um prazer. Não se confunde com o fio da amada de Teseu porque, em vez de levar para fora, para a liberdade, para o fim teleológico da narrativa, o fio textual no OuLiPo vai sempre mais para dentro do labirinto, dobrando-se progressivamente sobre si mesmo, a fim de fazer sobressair, cada vez mais, a contrainte que define a movimentação nesse tabuleiro. (PEREIRA, 2013, p. 190)
}

Os textos oulipianos também não buscam provocar grandes reflexões: "trata-se sempre aqui de um texto que se diz em vez de querer dizer algo a alguém. Como acontecimento, e não como mensagem, o poema oulipiano é jogo" (PEREIRA, 2012, p. 134), tendo como meta o "puro prazer da regra" (PEREIRA, 2012, p. 134). Ora, embora fazer "grande literatura" não fosse o objetivo principal dos escritores do OuLiPo, é inegável que alguns deles produziram, valendo-se de diversas contraintes, obras literárias. Assim, surge a questão: onde está o diferencial entre exercício individual de libertação de escrita e obra literária?

A análise de Pino (2004) fornece alguns subsídios para essa reflexão. A autora reconhece que a pesquisa analítica e sintética (PINO, 2004, p. 50) consiste apenas em um primeiro momento do OuLiPo. Pino reconhece um movimento de viragem a partir de 1967, quando da entrada de Georges Perec e Jacques Roubaud no grupo. Juntamente com Italo Calvino (membro a partir de 1973), esses escritores inauguram uma segunda etapa oulipiana: “em vez de fornecer novas estruturas ou inspirações para outros escritores, os novos membros queriam experimentar as regras formais, chegar ao seu limite e criar novas obras literárias a partir delas" (PINO, 2004, p. 51). É nesse 
momento que o OuLiPo deixa de ser um grupo "de diversão, para se transformar realmente em um tipo de movimento literário" (PINO, 2004, p. 51).

Haveria, ainda, uma terceira fase oulipiana, na qual as restrições não só mobilizam a produção do texto, como também determinam a estrutura e o enredo (como em A vida modo de usar, de Perec). Nessa última fase, a ênfase recai no processo criativo e na participação ativa do leitor (PINO, 2004, p. 52-53). Um dos diferenciais entre os exercícios de liberação da escrita (principal foco nos primórdios do OuLiPo) e as obras posteriores seria, portanto, a convocação do leitor para o jogo.

A organização da produção oulipiana em três fases reforça a gradação percebida entre os textos/jogos individuais (nos quais o leitor é um espectador) e os textos/jogos abertos à participação ativa do leitor. O jogo individual dialoga com outros textos mas, de certa forma, prescinde do leitor; a este, cabe a função de assistência. Ele pode fruir do jogo e acompanhar os lances da partida, mas sem engajar-se. Por sua vez, os jogos abertos à participação do outro inserem o leitor na arena e o convidam a jogar com o autor. Existem, por conseguinte, textos oulipianos que, além de se dizerem (PEREIRA, 2012, p. 134), dizem algo a alguém, comunicam-se, interpelam o outro, instaurando uma relação de parceria no jogo literário.

Perec confirma essa percepção: “A literatura começa [...] pela linguagem, na linguagem, essa transformação nada óbvia e nada imediata, que permite a um indivíduo tomar consciência, exprimindo o mundo, endereçando-se aos outros" (1992, p. 114) ${ }^{3}$. Para Perec, portanto, a literatura começa na e pela linguagem, e com ela diz algo (exprime o mundo) a alguém (se endereçando a outros); lembrando que esse endereçarse vale tanto para o leitor, como para os autores precedentes, num jogo intertextual. Nesses textos,

o autor (falante) tem os seus direitos inalienáveis sobre a palavra, mas o ouvinte também tem os seus direitos; têm também os seus direitos aqueles cujas vozes estão na palavra encontrada de antemão pelo autor [...]. A palavra é um drama do qual participam três personagens (não é um dueto mas um trio) (BAKHTIN, 2003, p. 328)

Destarte, as obras da segunda e terceira fase oulipianas vão além do jogo de referências (diálogo com os antecessores), abrindo-se à presença do leitor como "terceiro no diálogo" (PIRES, 2002, p. 43). Podemos considerar como exemplo dessa 
vertente o célebre Se um viajante numa noite de inverno (1979), de Italo Calvino, no qual o leitor é o protagonista.

Segundo Proença Filho (1999, p. 9), “O discurso literário traz, em certa medida, a marca da opacidade: abre-se [...] à capacidade e ao universo do receptor”. Com isso, perguntamo-nos: para que o leitor participe desse jogo com as obras oulipianas, é necessário que ele compreenda as regras que estruturam o texto? Há como entrar no jogo sem conhecimento prévio das regras?

Existem textos que, sem esse conhecimento prévio, são ininteligíveis para o leitor. Em sua opacidade, não há um sentido hermético: são textos cujo tema não está no conteúdo semântico, mas no processo de construção, na arquitetura textual; como diria Roubaud (1988, p. 90, tradução nossa), "Um texto escrito segundo uma regra fala dessa regra”. É o caso das Explorations à la limite (OULIPO, s.d.) de François Le Lionnais, nas quais as contraintes exploram os limites da Literatura. Le Lionnais propõe, assim, a redução de poemas a uma só letra, sonetos sem substantivos, adjetivos e verbos (compostos apenas de conectivos, advérbios e pronomes), dentre outras restrições extremas. Nesse tipo de texto, para que o leitor-partícipe se engaje na partida, é necessário que ele conheça a regra; do contrário, o texto será apenas uma série de palavras agrupadas de forma aparentemente aleatória.

Em contrapartida, existem obras oulipianas literariamente mais complexas, as quais aliam o conteúdo semântico ao uso das contraintes. Criam-se, desse modo, diferentes níveis de leitura e, nos patamares mais superficiais, o conhecimento das restrições não é compulsório para a interpretação. Como salienta Fux (2016, p. 30), “o não conhecimento específico da matemática não impede a leitura e o entendimento da obra", mas "o conhecimento do problema matemático discutido e apresentado em determinado texto aumenta substancialmente a potencialidade da obra". Não é preciso saber xadrez ou tarô para se ler A vida modo de usar ou $O$ castelo dos destinos cruzados; porém, é inegável que a leitura será mais rica se o leitor tiver esse entendimento.

O castelo dos destinos cruzados (2008), A vida modo de usar (2009) e A arte e a maneira de abordar seu chefe para pedir um aumento (2010) são romances da segunda e terceira fase do OuLiPo que consideramos complexos por aliarem o uso de restrições 
ao conteúdo semântico. Em decorrência dessa acepção, essas obras podem nos auxiliar a compreender de que forma se dá o diálogo escritor-leitor na literatura sob contraintes.

Italo Calvino, membro do OuLiPo a partir de 1973, publicou no mesmo ano $O$ castelo dos destinos cruzados (2008), já sob os parâmetros oulipianos. A restrição empregada por Calvino é o baralho de tarô: as histórias narradas em cada capítulo são compostas pela sequência das cartas. Os convivas, no castelo, não trocam palavras: "a travessia do bosque havia custado a cada um de nós a perda da fala" (CALVINO, 2008, p. 13), instaurando entre os interlocutores um diálogo silencioso, "mudo relato" (CALVINO, 2008, p. 17) prenhe de sentidos. Local de encontro, "O bosque é a perda de si, a mescla no todo" (CALVINO, 2008, p. 22).

As narrativas de $O$ castelo dos destinos cruzados têm caráter aberto; nascidas a partir de imagens, abrem a cada conviva uma interpretação diferente: “Apresentandonos a nós sob a figura do Cavaleiro de Copas [...], o nosso comensal queria provavelmente informar-nos sua condição de abastança [...] assim julguei” (CALVINO, 2008, p. 17); "Esperávamos impacientes uma outra carta mais explicativa" (CALVINO, 2008, p. 20); “a mímica do narrador já não nos ajudava e soía trabalhar à base de conjecturas" (CALVINO, 2008, p. 43). Também nesse romance, o leitor é apresentado à regra antes de entrar no jogo literário. Calvino inclui, em cada parágrafo, a carta que dá ensejo ao texto e, ao fim do capítulo, mostra ao leitor a sequência completa das cartas utilizadas na composição do enredo. O autor "entrega" o seu procedimento narrativo e, ao mesmo tempo, demonstra a sua potencialidade: o baralho de tarô traz possibilidades ilimitadas de criação: "as mesmas cartas apresentando-se numa ordem diversa não raro mudam de significado, e a mesma carta de tarô serve ao mesmo tempo a narradores que partem dos quatro pontos cardeais" (CALVINO, 2008, p. 63). Assim, todo o baralho empregado para criação de histórias no castelo é utilizado, em uma segunda parte do romance, para a criação de novos relatos - desta vez, na taverna dos destinos cruzados. Nas entrelinhas dos relatos, o autor define as restrições oulipianas que embasam sua obra:

não há um dado completo de uma vez: há um número finito de elementos cujas combinações se multiplicam por bilhões de bilhões, e dessas só umas poucas tomam forma e sentido e se impõem em meio a um polvilhar sem sentido e sem forma; como as setenta e oito cartas do maço do tarô. (CALVINO, 2008, p. 123-124) 
A contrainte de Calvino - narrativas criadas a partir do sorteio de cartas de tarô - permite que o escritor elabore textos calcados em um experimentalismo regrado:

\begin{abstract}
Os fregueses da taverna acotovelam-se em torno à mesa que se foi aos poucos cobrindo de cartas, esforçando-se por tirar dessa barafunda de tarôs a sua própria história, e quanto mais confusas e desconjuntadas se tornam essas histórias tanto mais as cartas esparramadas vão encontrando seu lugar num mosaico ordenado. Será apenas resultado do acaso, este desenho, ou talvez algum de nós o estará pacientemente estruturando? (CALVINO, 2008, p. 117)
\end{abstract}

No primeiro romance oulipiano de Calvino, o escritor é o principal artífice, o arquiteto que, pacientemente, estabelece as regras da estrutura e ordena o mosaico obtido por meio dessas regras, convidando o leitor a participar da construção.

Em A vida modo de usar (2009), publicado originalmente em 1978, Georges Perec constrói um hiper-romance multíplice e enciclopédico (CALVINO, 2005, p. 131), inventário de procedimentos romanescos. Como arquitetura básica de seu romance, Perec cria o esboço de um edifício parisiense, apresentando ao leitor a distribuição dos apartamentos; cada capítulo se passará em um desses imóveis. A disposição do edifício equivale a um tabuleiro de xadrez (quadrado 10x10), e a passagem do narrador pelos apartamentos segue o movimento da peça do cavalo (CALVINO, 2005, p. 135; FUX, 2016, p. 103).

O xadrez é uma contrainte em nível mais profundo, perceptível apenas para o leitor atento - aquele que, conhecedor das regras oulipianas, reconhece no processo interpretativo uma busca de pistas. Para o leitor que ainda precisa ser iniciado, o narrador perequiano explicita, no "Preâmbulo" outra contrainte como chave de leitura: “a arte do puzzle” (PEREC, 2009, p. 11). É, portanto, à luz da ideia de quebra-cabeça que o leitor é convidado a ler os romances contidos em $A$ vida modo de usar, todos eles embaralhados entre si. O romance traz, embaralhados, enredos para 179 romances potenciais.

O narrador perequiano rejeita os puzzles padronizados, feitos à máquina, afirmando que só lhe dão prazer os quebra-cabeças feitos à mão, por artesãos (PEREC, 2009, p. 12-13). Ele é, pois, como todo escritor oulipiano, um construtor de puzzles, compondo a imagem inteira, desmembrando-a em partes (segundo contraintes por ele 
determinadas) e apresentando as peças ao leitor. Perec evidencia que a presença de um interlocutor, ainda que imaginário, faz parte do processo de criação:

\begin{abstract}
A arte do puzzle começa com os puzzles de madeira cortados à mão, quando a pessoa que os fabrica se propõe apresentar a si mesma todas as questões que o jogador deverá resolver; quando, em vez de deixar o acaso enredar as pistas, decide interferir pessoalmente para criar a astúcia, o ardil, a ilusão. (PEREC, 2009, p. 13)
\end{abstract}

Sob essa ótica, o escritor vê no leitor um adversário, desafiando-o por meio de ciladas e informações enganadoras (PEREC, 2009, p. 13). Se aceitar o convite, o leitorarmador de puzzles manipulará as peças e eliminará as pistas falsas, numa tentativa de montar "a imagem a ser reconstruída" (PEREC, 2009, p. 13). Seu papel, portanto, é ativo, e sua participação é desejada pelo escritor-construtor. É por esse motivo que o narrador perequiano elucida:

\footnotetext{
Podemos deduzir daí algo que é, sem dúvida, a verdade última do puzzle: apesar das aparências, não se trata de um jogo solitário - todo gesto que faz o armador de puzzles [o leitor], o construtor [escritor] já o fez antes dele; toda peça que toma e retoma, examina, acaricia, toda combinação que tenta e volta a tentar, toda hesitação, toda intuição, toda esperança, todo esmorecimento foram decididos, calculados, estudados pelo outro. (PEREC, 2009, p. 14)
}

O leitor separa as peças embaralhadas buscando atribuir-lhes uma certa unidade: "só quando reunidas as peças assumirão um caráter legível, adquirirão sentido; considerada isoladamente, a peça de um puzzle não quer dizer nada; não passa de pergunta impossível, desafio opaco" (PEREC, 2009, p. 11). A unidade total, no entanto, é utópica, e o caráter fecundo e aberto de $A$ vida modo de usar resulta, justamente, dessa impossibilidade: o livro não tem cem, mas 99 capítulos - "uma pequena saída para o inacabado", segundo Calvino (2005, p. 136) - e a personagem Bartlebooth, armador de quebra-cabeças, morre com a última peça de seu puzzle na mão, deixando o jogo incompleto. A incompletude é a riqueza da obra literária, que sempre escapa a sentidos fechados e nunca se esgota.

O puzzle perequiano é, ainda, partida entre o escritor oulipiano e a tradição literária precedente. Cada peça de seu quebra-cabeça romanesco resgata puzzles anteriores - como o fazem os oulipianos, que, como bons algebristas, restauram procedimentos e restrições já existentes na Literatura. 
No livro $A$ arte e a maneira de abordar seu chefe para pedir um aumento (2010), publicado postumamente em 2008, Perec constrói seu labirinto literário a partir da estrutura de um organograma. Não é um feito inédito: também Raymond Queneau produziu textos tendo o "organograma como limite gerador" (MAGNÉ, 2010, p. 72). Perec e Queneau produziram obras de literatura ramificada, "lançando mão dos percursos em cadeia dos grafos" (MAGNÉ, 2010, p. 73). Em seu livro, Perec explora linearmente todos os percursos possíveis apresentados no organograma "A arte e a maneira de abordar seu chefe imediato". Esse método de escrita, calcado na exploração sucessiva de todas as eventualidades, pode parecer enfadonho a princípio, mas o desenvolvimento da narrativa instaura a diferença na repetição e mobiliza o leitor: a introdução de pequenas variações em cada trecho propõe, ao leitor, que veja "mais de perto onde se escondem as diferenças. Lançando-se à exploração de um rigoroso organograma, o leitor se encontra finalmente num jogo de sete erros muito mais sofisticado" (MAGNÉ, 2010, p. 83). Nesse livro, particularmente, o diálogo entre narrador e narratário fundamenta a obra, apresentando-se já nas primeiras linhas: "Tendo refletido judiciosamente tendo tomado coragem você decide procurar seu chefe imediato para pedir um aumento vai então procurar seu chefe imediato" (PEREC, 2010, p. 7). O organograma apresentado logo ao início do texto entrega ao leitor o roteiro, a regra a ser seguida. Nesse caso, o leitor tem conhecimento da contrainte antes de participar do jogo literário.

\section{COLECIONISMO EM DIÁLOGO}

Vemos, portanto, que o oulipiano é um colecionador de referências e procedimentos. Reconhecemos dois tipos de colecionador: o egoísta e o que compartilha. O colecionador egoísta é um acumulador, que guarda sua coleção para si. Por outro lado, o colecionador que compartilha é generoso, ele dialoga com o leitor, mostra a ele sua coleção e o convida a manipulá-la.

Um colecionador egoísta toma sua obra para si, tendo assim acesso exclusivo à obra e seu percurso - o qual, na acepção da imanência, confunde-se com a obra. No âmbito textual, seu discurso seria aquele "que não se dirige a ninguém e não pressupõe resposta" (BAKHTIN, 2003, p. 323). Enquanto o texto de um colecionador egoísta é 
fechado, um colecionador que partilha abre espaços para que a experiência se propague. Para esse último, escrever está ao lado de organizar, classificar e distribuir seu inventário de lugares, cheiros, sons, cores, experiências, e as relações de propriedade ficam em segundo plano, abrindo espaço para uma escrita compositiva e dialógica.

Consideramos, aqui, o dialogismo bakhtiniano, em que o discurso, ao implicar sujeitos, "presume destinatários e suas respostas" (PIRES, 2002, p. 42); a principal característica do enunciado "é o seu direcionamento a alguém, o seu endereçamento" (BAKHTIN, 2003, p. 301). Nessa relação dialógica, "não há passividade. Nela, o discurso é um jogo, é movimento, tentativa de transformação e mesmo subversão dos sentidos. O sentido de um discurso jamais é o último: a interpretação é infinita" (PIRES, 2002, p. 42). O diálogo "é o acontecimento do encontro e interação com a palavra do(s) outro(s)" (PIRES, 2002, p. 44). É nesse encontro com o outro, nessa relação que se estabelece entre autor, leitor e obra, que a interpretação se abre ao infinito.

Tomamos o colecionismo como atitude e experiência com o texto. Para um colecionador de referências, o texto se relaciona com outros. Como aponta Bakhtin (2003, p. 300), “o enunciado é um elo na cadeia [...] e não pode ser separado dos elos precedentes que o determinam [...], gerando nele atitudes responsivas diretas e ressonâncias dialógicas". O diálogo com os antecessores existe em ambos os tipos de colecionador; porém, alguns textos oulipianos comprometem-se com os antecessores e, ainda, com os interlocutores, considerando a perspectiva do leitor - o terceiro no diálogo (BAKHTIN, 2003, p. 328), o jogador que manipulará o texto e que, assim, perceberá as relações entre o texto e seus antecessores e/ou o texto e suas regras de formação.

Calvino (2005, p. 136-137) diz que "o demônio do colecionismo paira continuamente sobre as páginas de Perec". Mas esse colecionismo, essa enumeração ou listagem próprias da escrita perequiana, conferem-lhe um vasto repertório, o qual permite saltar da axiomática à variação. Sua ordenação e referências servem-lhe de crivo ao acaso, fazendo sair disso uma criação que se abre às interpretações do leitor.

Os romances $O$ castelo dos destinos cruzados, $A$ vida modo de usar e $A$ arte e a maneira de abordar seu chefe para pedir um aumento são narrativas construídas por colecionadores compartilhadores. Esses autores convocam o outro a adentrar em sua coleção, propondo que o convidado não só admire os itens colecionados e sua 
disposição, mas também os manipule e os redistribua. Ao propor que o texto seja lidoescrito pelo leitor, que seja de algum modo acessível a ele, as regras passam a ser compartilhadas e o texto produz ecos, reverberando interpretações e propagando-se no tempo. É nesse sentido que partilhamos a iteração, por parte do OuLiPo e de pesquisadores, dos nomes de Perec e Calvino, por exemplo, como dois dos mais relevantes do grupo.

\section{CONCLUSÕES}

O autor oulipiano é um jogador, um arquiteto, um algebrista, um colecionador. Assume o caráter regrado da linguagem e serve-se dele para, levando-o ao limite, produzir uma literatura potencial. As contraintes são disparadoras de uma escrita que se contrapõe à liberdade absoluta, aos automatismos, à inspiração.

O grupo inventaria procedimentos preexistentes e solidifica a escrita em bases matemáticas, assumindo caráter estratégico de jogo e estrutura arquitetônica. Consideramos essa arquitetura labiríntica, porque os caminhos se imbricam e percorrêlos torna-se tão importante quanto sair dele, ou fazer algo sair dele, colocando a imanência em jogo nesse percurso.

Concluímos, a partir das análises de obras e comentadores, e do desenvolvimento dos argumentos apresentados, que em algumas obras oulipianas especialmente as que reverberam sentidos no leitor e propagam-se como referências no tempo -, a participação do outro não é de mero espectador, mas de copartícipe. É esse permitir que o outro adentre o texto, esse partilhar com o leitor que caracteriza o oulipiano como um colecionador generoso. Caso contrário, quando o escritor assume um caráter de colecionador egoísta, não existe diálogo - no sentido bakhtiniano - e a obra deixa de produzir ecos.

A participação do leitor não possui caráter fundante para a produção do escritor oulipiano; na mesma medida, ela não é dispensável. As três fases da produção do OuLiPo percorrem o caminho de fortalecimento nessa relação autor-leitor: de jogos individuais e egoístas por parte do escritor, prescindindo de um terceiro, aos abertos à participação ativa do leitor, interpelando-o e instaurando uma relação de parceria no jogo literário. 


\section{Referências}

BAKHTIN, Mikhail. Estética da criação verbal. 4. ed. Tradução de Paulo Bezerra. São Paulo: Martins Fontes, 2003.

BÉNABOU, Marcel; ROUBAUD, Jacques. Qu'est-ce que l'Oulipo?. s.d. Disponível em: https://www.oulipo.net/fr/oulipiens/o. Acesso em: 17 abr. 2020.

BOYER, Carl et al. História da matemática. Tradução de Helena Castro. São Paulo: Blucher, 2012.

BRETON, André. Manifesto do Surrealismo (1924). Disponível em:

http://www.ufscar.br/ cec/arquivos/referencias/Manifesto\%20do\%20Surrealismo\%20\% 20Andr\%20Breton.htm. Acesso em: 25 maio 2020.

CALVINO, Italo. O castelo dos destinos cruzados. 2. ed. Tradução de Ivo Barroso. São Paulo: Companhia das Letras, 2008.

CALVINO, Italo. Seis propostas para o próximo milênio: lições americanas. 3. ed. Tradução de Ivo Barroso. São Paulo: Companhia das Letras, 2005.

CARNEIRO, Maria Clara da Silva Ramos Carneiro. A nova "bande dessinée": l'Association e o OuBaPo. In: DALCASTAGNÈ, Regina (org.). Histórias em quadrinhos: diante da experiência dos outros. Vinhedo, SP: Horizonte, 2012. p. 101117.

DELEUZE, Gilles; GUATTARI, Félix. O que é a filosofia? Tradução de Bento Prado Jr. e Alberto Alonso Muñoz. Rio de Janeiro: Editora 34, 2010.

DETIENNE, Marcel. A escrita de Orfeu. Tradução de Mário da Gama Kury. Rio de Janeiro: Jorge Zahar, 1991.

D'ONOFRIO, Salvatore. Teoria do texto: prolegômenos e teoria narrativa. São Paulo: Ática, 2001.

FUX, Jacques. Literatura e matemática: Jorge Luis Borges, Georges Perec e o Oulipo. São Paulo: Perspectiva, 2016.

GENETTE, Gérard. Palimpsestos: a literatura de segunda mão. Tradução de Luciene Guimarães e Maria Antônia Ramos Coutinho. Belo Horizonte: FALE/UFMG, 2006.

JAMES, Alison. Constraining chance: Georges Perec and the Oulipo. Evanston, IL: Northwestern University Press, 2009.

MACHADO, Arlindo. Pré-cinemas e pós-cinemas. 5. ed. São Paulo: Papirus, 2008. 
MAGNÉ, Bernard. Posfácio. In: PEREC, Georges. A arte e a maneira de abordar seu chefe para pedir um aumento. Tradução de Bernardo Carvalho. São Paulo: Companhia das Letras, 2010. p. 71-83.

MOLINA, Enrique. Surrealismo Novo Mundo. In: PONGE, Robert (Org.). Surrealismo e novo mundo. Porto Alegre: Editora da Universidade, 1999. p. 23-25.

OULIPO. Explorations à la limite. OuLiPo, s.d. Disponível em:

https://www.oulipo.net/fr/contraintes/explorations-a-la-limite. Acesso em: 05 jun. 2020.

PEREC, Georges. A arte e a maneira de abordar seu chefe para pedir um aumento. Tradução de Bernardo Carvalho. São Paulo: Companhia das Letras, 2010.

PEREC, Georges. A vida modo de usar: romances. Tradução de Ivo Barroso. São Paulo: Companhia das Letras, 2009.

PEREC, Georges. L. G.: une aventure des années soixante. Paris: Seuil, 1992.

PEREC, Georges. Palindrome. Paris: Denöel, 2019.

PEREIRA, Vinícius Carvalho. A contrainte como jogo retórico na poética do OuLiPo, Matraga, Rio de Janeiro, v. 20, n. 33, jul./dez. 2013, p. 174-193. Disponível em: https://www.e-publicacoes.uerj.br/index.php/matraga/article/view/19778/14262. Acesso em: 06 abr. 2020.

PEREIRA, Vinícius Carvalho. A escrita como jogo: desafios e contraintes na literatura do OuLiPo, Outra Travessia, n. 13, Florianópolis, 2012, p. 119-134. Disponível em: https://periodicos.ufsc.br/index.php/Outra/article/view/2176-8552.2012n13p119/24142. Acesso em: 06 abr. 2020.

PERRONE-MOISÉS, Leyla. Mutações da literatura no século XXI. 1. ed. São Paulo: Companhia das Letras, 2016.

PINO, Claudia Amigo. A ficção da escrita. Cotia, SP: Ateliê Editorial, 2004.

PROENÇA FILHO, Domício. A linguagem literária. 7. ed. São Paulo: Ática, 1999.

QUENEAU, Raymond. Cent mille milliards de poèmes, 1961. Disponível em: http://www.bevrowe.info/Queneau/QueneauRandom_v5.html. Acesso em: 11 mar. 2021.

QUENEAU, Raymond. Exercícios de estilo. Tradução de Luiz Rezende. Rio de Janeiro: Imago, 1995.

ROUBAUD, Jacques. A bela Hortense. Tradução de Teresa Meneses. Porto: Asa, 1993.

ROUBAUD, Jacques. Deux principes parfois respectés par les travaux oulipiens. In: OULIPO. Atlas de littérature potentielle. Paris: Gallimard, 1988. p. 90. 
ROUBAUD, Jacques. Graal fiction, 1978. Disponível em:

http://416301eb4f696ae919171bbe6834fdee.todanoiva.com.br. Acesso em: 11 mar. 2021.

ROUBAUD, Jacques. Os animais de todo mundo. Tradução de Paula Glenadel e Marcos Siscar. São Paulo: Cosac Naify, 2006.

SCHÖPKE, Regina. Dicionário filosófico: conceitos fundamentais. São Paulo: Martins Fontes, 2010.

SILVA, Natália Ubirajara. A sinfonia narrativa de Augusto Abelaira: a metaficção em "O Triunfo da Morte". 2009. 99f. Dissertação (Mestrado em Letras) - Instituto de Letras, Universidade Federal do Rio Grande do Sul, Porto Alegre, 2009.

TAVARES, Braulio. O hiper-soneto de Queneau. Mundo Fantasmo. 15 mar. 2008. Disponível em: http://mundofantasmo.blogspot.com/2008/03/0254-o-hiper-soneto-dequeneau-1312004.html. Acesso em: 04 jun. 2020.

ZOURABICHVILI, François. O vocabulário de Deleuze. Tradução de André Telles. Rio de Janeiro: Relume Dumará, 2004.

Recebido em: 20/01/2021

Aceito em: 11/03/2021

\footnotetext{
${ }^{1}$ No original: "Et un AUTEUR oulipien, c'est quoi? C'est "un rat qui construit lui-même le labyrinthe dont il se propose de sortir". Un labyrinthe de quoi? De mots, de sons, de phrases, de paragraphes, de chapitres, de livres, de bibliothèques, de prose, de poésie, et tout ça...".

${ }^{2}$ No original: "Que font les OULIPIENS, les membres de 1'OULIPO (Calvino, Perec, Marcel Duchamp, et autres, mathématiciens et littérateurs, littérateurs-mathématiciens, et mathématiciens-littérateurs)? Ils travaillent".

3 Tradução nossa.
} 